REVISTA PERUANA DE INVESTIGACIÓN EDUCATIVA $2018, \mathrm{No} .10$, p p.83-98

\title{
Estudiando para ser alguien en la vida: consecuencias del fracaso educativo en los jóvenes de Nauta
}

\section{Maite Bustamante de Almenara}

$\overline{\text { Programa de Pueblos Indígenas de la Defensoría del Pueblo }}$

maite.bustamante.25@gmail.com 


\title{
Estudiando para ser alguien en la vida: consecuencias del fracaso educativo en los jóvenes de Nauta
}

\section{Resumen}

En la ciudad de Nauta, la carrera profesional es percibida como el único medio a disposición de los jóvenes para acceder a una vida significativa. En un contexto de precariedad y discriminación, donde las estrategias de vida de las generaciones pasadas se consideran insostenibles; la educación superior ofrece la esperanza de acceder a nuevas alternativas. No obstante, por falta de recursos, la mayoría no logra acceder a esta meta. El fracaso enfrenta a los jóvenes a una serie de dilemas, presiones familiares y desilusiones personales ante las cuales algunos incluso toman la decisión de suicidarse. En este artículo se analizan los discursos en torno a la educación en Nauta que contribuyen a poner a los jóvenes en una situación de riesgo ante el fracaso en acceder a una educación universitaria. La información a continuación es parte de una investigación más amplia sobre suicidios de jóvenes en Nauta, para la cual se realizó un trabajo de campo de dos meses en el año 2016.

Palabras clave: Salud mental, suicidio, educación y desarrollo, educación, igualdad de oportunidades

\section{Studying for becoming someone in life: consequences of educational failure among Nauta youth}

\begin{abstract}
In the city of Nauta, achieving undergraduate studies is perceived as the only available way for young people to access to a significant life. In a context of scarcity and discrimination, where life strategies of past generations are considered unsustainable, Higher Education brings hope of accessing to new alternatives. However, due to the lack of resources, most of young people are unable to succeed in this goal. This failure faces them into a series of dilemmas, family pressures and personal disappointments, which even lead some of them into committing suicide. This article analyses the education-related discourses in Nauta that contribute to put young people into a risky situation when failing in achieving undergraduate studies. The data presented is part of a wider research regarding suicides among young people in Nauta, for which a two-months-field-work was carried on in 2016.

Keywords: Mental health, suicides, education and development, education, equality of opportunities
\end{abstract}




\section{La promesa de la educación}

Desde el siglo XX, especialmente desde su segunda mitad, el Perú es escenario de una lucha individual, familiar y comunal por parte de campesinos e indígenas en busca de garantizar el acceso de sus hijos a la educación. Esta lucha parte de la premisa de que, por medio de la educación, los hijos podrán dejar atrás la pobreza, la discriminación, los engaños y los abusos, que desde la época colonial tiñen la historia de las poblaciones rurales. Del mismo modo, se basa en la idea de que este canal les permitirá defenderse, conseguir trabajos bien remunerados y volverse ciudadanos valorados y respetados. En otras palabras, aspiran a que la educación les permita acceder a una real y justa integración con la sociedad nacional y el mercado (Ames, 2002, p. 12-55; Ansión, 1995, p. 508-514; Degregori, 2007, p. 7).

Este artículo presenta un caso en el que esta lucha fracasa. Es decir, se trata de un caso en el que, pese a todos los esfuerzos realizados, la educación no mejoró significativamente las posibilidades de los hijos de acceder a las condiciones de vida esperadas. Se ha discutido ampliamente sobre los factores que pueden llevar a este tipo de fracaso, haciendo referencia a elementos como la calidad de la educación, las brechas de acceso, la desigualdad de oportunidades, los enfoques pedagógicos, los factores estructurales, entre otros ${ }^{1}$. Muchos de esos factores están presentes en el caso de Nauta.

No obstante, en esta oportunidad, el foco de la discusión es otro: se evalúa en qué medida los discursos y las prácticas asociadas a la promesa de la educación contribuyen a poner a los jóvenes en una situación de riesgo. De esa manera, este artículo busca discutir sobre el impacto negativo que pueden tener algunos discursos bienintencionados en el ámbito educativo. Asimismo, apunta a reflexionar hasta qué punto los términos para la integración social ofrecidos por esta promesa pueden no ser los más adecuados.

La información obtenida es producto de un trabajo de campo de 2 meses realizado en el año 2016 en la ciudad de Nauta. En este, se aplicó 65 entrevistas semiestructuradas a escolares y jóvenes de hasta 25 años, tanto hombres como mujeres. La mayoría pertenecían a los colegios públicos Miguel Grau Seminario y Nuestra Señora de Loreto, y fueron seleccionados mediante el método bola de nieve. Asimismo, se entrevistó a 10 adultos relacionados con el tema ${ }^{2}$ y se revisó registros locales, entre ellos, 31 entrevistas realizadas por la Radio Ucamara durante el 2013 a madres, padres, hermanos y viudas de jóvenes que se suicidaron.

El objetivo del trabajo de campo fue determinar por qué en Nauta existe una alta incidencia de suicidios juveniles. Por ese motivo, el foco de atención

1. Al respecto, puede consultarse Ames (200), Ansión (1995) y Benavides (2007).

2. Algunos habían estudiado este fenómeno de manera periodística, otros eran familiares de víctimas y otros se habían acercado al tema a partir de su trabajo con adolescentes. 
se concentró en tres aspectos: a) conocer las expectativas de vida y las dificultades que enfrentan los jóvenes nautinos; b) recoger las percepciones sobre por qué ocurren suicidios juveniles, quiénes lo cometen y desde cuándo; y c) reconstruir experiencias de suicidios o intentos de suicidio. En un primer momento, la educación no fue prevista como un foco de atención. Sin embargo, conforme fue avanzando la investigación, la dimensión educativa se convirtió en un aspecto fundamental, por aparecer como el telón de fondo del grueso de los casos de suicidio.

\section{El sacrificio de los padres}

La ciudad de Nauta es una capital de provincia en el departamento de Loreto. Desde el siglo XIX, es un puerto estratégico en el comercio fluvial entre Perú y Brasil (Agüero, 1994). Pese a ello, al 2016, la mayor parte de su economía era informal, el $69 \%$ de su población calificaba como pobre extremo y el $27 \%$ como pobre, y solo una minoría tenía acceso a servicios de agua y saneamiento.

Desde el año 2001, Nauta experimenta un crecimiento poblacional vertiginoso. En el 2016, sobrepasó los 30,000 habitantes, lo que representó un crecimiento de un $50 \%$ con respecto al 2006. Este acelerado crecimiento inició con el proyecto de construcción de la carretera Iquitos-Nauta, el cual reducía el tiempo de viaje entre ambas localidades de aproximadamente 18 horas a tan solo una hora y media.

El inicio de la construcción de la carretera creó una expectativa muy grande. Políticos y funcionarios públicos predicaban descuidadamente la llegada del progreso. En ese contexto, muchas familias de las comunidades de la ribera, deseosas de compartir los beneficios anunciados, decidieron dejar sus tierras para probar suerte en la ciudad. La expectativa de que el progreso nautino permitiría a sus hijos acceder a una educación superior que, en última instancia, les daría acceso a una mejor calidad de vida fue un elemento central en la toma de esa decisión.

No obstante, empezar de nuevo no fue fácil. El rápido crecimiento poblacional ocasionó una fuerte presión por la tierra. Se invadieron terrenos que antes eran usados como chacras o como monte para recolectar recursos forestales, y se concesionaron terrenos estatales. Ello imposibilitó a la mayoría de migrantes conseguir un terreno agrícola del tamaño del que dejaron en su comunidad. Adicionalmente, el uso irresponsable de los recursos forestales durante las invasiones desorganizadas y la contaminación producida por actividades extractivas en la zona contribuyeron a que disminuya drásticamente la productividad de los suelos y la cantidad de pescado disponible. Estos factores obligaron a las familias migrantes a abandonar la economía de autosubsistencia y a adaptarse al sistema laboral nautino.

El grueso de la población empezó a trabajar como vendedor, carguero, peón, niñera, barrendera, motocarrista o algún otro oficio no especializado. La

86 I gran mayoría de esos empleos eran informales, inestables y ofrecían salarios 
muy bajos. El rápido crecimiento poblacional generó una sobreoferta de mano de obra, lo que permite hasta el día de hoy que el sueldo promedio ronde los 200 soles mensuales, es decir, un $80 \%$ menos que lo establecido como el sueldo mínimo nacional. Los sueldos son tan bajos que no alcanzan más que para sobrevivir. Las familias viven al día y requieren que varios de sus miembros trabajen para cubrir los gastos no alimenticios, como útiles escolares, ropa o alguna medicina. Incluso, en ocasiones, un solo empleo por persona puede ser insuficiente, por lo que se suele combinar diversas estrategias económicas por persona.

Pese a que Nauta no ofreció buenas oportunidades laborales ni de vivienda a los migrantes, jóvenes y adultos coinciden en que migrar a Nauta fue una buena decisión. Ello se explica haciendo referencia a las posibilidades de futuro: a la posibilidad de que la siguiente generación acceda a una educación superior y, de esa manera, a un mejor trabajo que permita mejorar la situación de toda la familia. Desde esa lógica, la apuesta de los migrantes fue, a fin de cuentas, un sacrificio por sus hijos.

"Te voy a dejar con tu recuerdo que es tu educación, tu herencia, tu educación. Comiendo, no comiendo, te voy a dar para que tenga usted". Así le decía a ella: "ya que ninguno de tus hermanos mayores ha querido estudiar, siquiera usted, hija; yo quiero que ustedes sean algo". (Madre de familia, 2016)

\section{Para "ser alguien en la vida"}

La lucha por la educación de las poblaciones rurales en el Perú, desde sus inicios, está muy ligada a adquirir prestigio. Lo que importa no es tanto qué aprendes, sino en quién te puedes convertir con lo que has aprendido. Esta idea cobra un especial sentido si consideramos que las relaciones de opresión y subordinación que motivan esta lucha son, en gran medida, herencia de una sociedad colonial estamental (Ansión, 1995, p. 511-513). El hablar castellano, el saber leer y escribir, el ser de la costa o de la sierra, el ser blanco o indio, el vivir en las zonas urbanas o rurales son todos signos de la jerarquía que uno ocupa en la sociedad, y, por ende, de sus posibilidades y oportunidades en la vida.

En esa línea, Montoya (1980, p. 309-316) describe el acceso de los campesinos a la escuela en Puquio a inicios del siglo XX como una rebeldía manifiesta al orden social y una afrenta al sistema de opresión feudal dominante de la época. Mediante la escuela, los campesinos se desligaban de aquellos signos que los identificaban con su origen subordinado y se apropiaban de los signos que tradicionalmente habían sido exclusivos de los grupos dominantes. Mediante este proceso, ellos adquirían nuevos derechos y posibilidades, pero lo hacían mediante el rechazo de su cultura, la cual se veía fuertemente afectada. Esta manera dicotómica de comprender la identidad que uno deja y la 
identidad que uno adquiere mediante la escuela se observa también en el caso nautino. La gran mayoría de los migrantes que llegaron a Nauta descienden de la población indígena Kukama, pero no se identifican como tales. Al contrario, muchos buscan desligarse de aquellos rasgos que evidencian su origen étnico. Según algunos autores, estas actitudes son parte de una estrategia de adaptación a un medio social caracterizado por discriminar y marginar a los indígenas (Berjón y Cadenas, 2011; Rivas, 2000; Stocks, 1981).

Desde su primer contacto con población occidental en 1557, la historia de la población Kukama ha sido marcada por una constante de relaciones de dominación y abuso. Las reducciones jesuíticas en el siglo XVII, el trabajo forzado en haciendas, las correrías en la época del caucho y la contratación como obreros industriales asalariados son algunos de los principales hitos que marcaron la disminución de esta población, su desintegración étnica y su empobrecimiento (Agüero, 1994; Berjón y Cadenas, 2009; Regan, 2008; Stocks, 1983).

En Nauta, ser indígena es lo mismo que ser pobre, que no tener voz, que no ser nadie, que tener una vida de sufrimiento. Por esas razones, el mundo indígena y lo que lo distingue es percibido por muchos como un rezago del pasado que debe desaparecer. Asimismo, la educación $-\mathrm{y}$, particularmente, la educación superior - es percibida como el canal que permitirá a los jóvenes acceder a un mundo distinto, uno en el que puedan tener una vida digna.

Los docentes del colegio desempeñan un rol fundamental en la formación del discurso que valora la profesión como algo positivo y del presente, y consideran lo indígena como algo negativo y del pasado. Ellos inculcan a sus alumnos la aspiración a "superar" a sus padres y a dejar la chacra. Asimismo, describen como alumnos exitosos a aquellos que lograron ser profesionales. Los padres de familia adoptan un discurso parecido. Constantemente, incentivan a sus hijos a que sean "aquello que ellos no pudieron ser" e insisten en los beneficios de contar con una carrera profesional. En líneas generales, toda la escolaridad es presentada como un canal para que los alumnos logren ser profesionales.

Consecuentemente, cuando uno les pregunta a los escolares nautinos qué quieren hacer cuando terminen el colegio, la gran mayoría responden que quieren ser profesionales. De 45 escolares consultados, 36 respondieron que aspiraban a una carrera profesional; 9, a una técnica; y ninguno contestó que aspira a una actividad no profesional.

\section{El incumplimiento de la promesa}

Los escolares nautinos enfrentan una serie de problemas que dificultan y, en ocasiones, impiden que puedan competir con alumnos de contextos nacionales más favorables. Muchos de esos problemas tienen como trasfondo la situación de pobreza en la que están inmersas sus familias. La mayoría de los escolares en Nauta trabaja durante el verano para cubrir el costo de sus útiles escolares. 
Debido a los bajos sueldos, dos meses de trabajo a tiempo completo alcanzan casi únicamente para ese fin. Adicionalmente, muchos necesitan trabajar para apoyar a la economía de sus familias. Evidentemente, el cansancio y, en las épocas más difíciles, el hambre son factores que afectan su aprendizaje.

Dicho aprendizaje también es afectado por las carencias de los colegios públicos a los que asisten que, por las limitaciones de sus docentes y sus recursos materiales, están lejos de ser competitivos. Los alumnos que intenten estudiar una carrera universitaria deberán ser doblemente recursivos, hábiles y sacrificados para suplir con autonomía las brechas educativas de las que parten. Así mismo, lo tendrán que ser para encontrar la manera de financiar sus estudios.

Nauta cuenta con un instituto tecnológico, pero no con una universidad. Por ese motivo, la mayoría de jóvenes nautinos planea mudarse a Lima o Iquitos al terminar el colegio, considerando a Iquitos como la opción más probable y a Lima como la más deseable. Para elegir a dónde migrar, pesa mucho el tener familia en el lugar de destino, pues ello reduce de manera significativa los costos de vida.

Los nautinos que postulan a una universidad esperan contar con un apoyo económico de sus padres. No obstante, debido a las difíciles condiciones económicas, ello generalmente no es suficiente. Por ese motivo, muchos se esfuerzan por desarrollar estrategias económicas complementarias. En ocasiones, los padres apoyan al hijo mayor para que estudie; luego, este apoya a su hermano menor; y así sucesivamente. En otros casos, los jóvenes planean trabajar mientras estudian, aunque la mayoría comenta que esto es muy difícil y agotador. Otros piden a sus padres que los ayuden a estudiar una carrera técnica, para luego trabajar, ahorrar y pagarse estudios universitarios. Otros buscan entrar a instituciones como La Marina, que no requiere certificado de estudios y les paga desde el inicio. Llama la atención el hecho de que muy pocos alumnos consideren postular a una beca. En muchos casos, ello se debe al desconocimiento de las becas que hay y, en otros, a las dificultades que enfrentan los alumnos para cumplir con los requisitos de la postulación.

Sin necesidad de ir más lejos, es claro que los escolares nautinos promedio tienen escasas probabilidades de acceder a y culminar una educación superior. Por ese motivo, en la práctica, la mayoría de los que lo intenta fracasa.

Entrevistadora: ¿Cuántos jóvenes realmente pueden llegar a acceder a una carrera?

Entrevistado: Más o menos 15\%, de repente mucho; de repente, $10 \%$ logra ingresar a una universidad. Los demás logran encontrar un trabajito, una carrera corta o están estudiando por correspondencia. Algunas universidades también vienen a dar clases presenciales una vez a la semana y, de esa manera, algunos jóvenes van profesionalizándose. Otros ya no logran lo que pensaban, pero terminan haciendo lo que 
van pudiendo. Dedicarse a lo que nunca pensaron, pero simplemente porque están ahí ya metidos. (Profesor, 2016)

La mayoría de los jóvenes que fracasaron en su intento de acceder a una carrera universitaria identifica como la principal causa de su fracaso las dificultades económicas que enfrentaron. Algunos desistieron, porque no podían mantenerse o pagar las mensualidades; otros, porque tenían la obligación de apoyar económicamente a sus padres o a sus hermanos menores.

Entrevistadora: ¿Terminaste el colegio, fuiste a Lima a estudiar y de frente empezaste a trabajar?

Entrevistada: No, recién a medio año que había salido del colegio. Recién ahí, empecé a trabajar, porque mis padres no tenían recursos para que siga estudiando. Me decidí ponerme a trabajar para poder seguir estudiando, pero no pude.

Entrevistadora: ¿Qué trabajo conseguiste?

Entrevistada: De atender en un lugar donde venden repuestos de autos y de motos.

Entrevistadora: ¿Y lo que te pagaban te alcanzaba para ahorrar?

Entrevistada: No, no ahorraba nada, pues. Tenía que enviar a mi mamá y no quedaba casi nada. A veces, no podía ni comprar mi ropa. (Mujer, 24 años, 2016)

En el caso de las mujeres, tener hijos es otra razón que influye en su decisión de abandonar definitivamente los esfuerzos para estudiar. Algunas, sin embargo, lo hacen con el apoyo de sus parejas y de sus padres. Esta causa de deserción no es poco significativa: de acuerdo con el registro del centro de salud, en el año 2015, hubo 81 casos de jóvenes entre 12 y 17 años que salieron embarazadas en la ciudad de Nauta. Otra razón que motiva la deserción femenina es tener pareja. Muchas alumnas coinciden en que tienen que mantenerse solteras para poder terminar sus estudios. Esto se debe a que, una vez emparejadas, los hombres les exigen que asuman roles o responsabilidades que les impiden seguir estudiando.

\section{Lo que implica el fracaso}

Pese a que la mayoría de escolares nautinos siente que ha tomado la decisión de estudiar una carrera profesional únicamente por sus intereses personales, al conversar con ellos sobre sus proyectos de vida, es evidente que, al igual que lo que sucede con muchos otros jóvenes rurales peruanos (Ames 2002:45), sus proyectos educativos se entrecruzan con estrategias económicas familiares a largo plazo.

Aquí no hay trabajo y yo tengo que mantener a mis padres. Tengo que ir a otra parte para ganar bien para mantener a mis padres. También, tengo un hermano menor y tengo que trabajar para cuando sea grande. 
Tengo que trabajar para hacerlo estudiar a él también. (Mujer, 15 años, 2016)

Esta manera de planear el futuro se fundamenta sobre una lógica que va más allá del interés personal que cada quien puede tener por ayudar a su familia. Recordemos que el sacrificio de los padres migrantes los condujo a una vida muy precaria. Este factor tuvo una repercusión en la socialización de sus hijos. Muchos de estos crecieron escuchando a sus padres decir que todo lo hacían por ellos, que eran su esperanza, que eran quienes los sacarían de esa situación de pobreza.

Consciente o inconscientemente, esas frases generan un alto grado de presión, porque implican que, de fracasar, los hijos no podrán retribuir el sacrificio mejorando la vida de sus padres. También, generan presión los discursos que el alumno escucha en casa, en el colegio y en los medios de comunicación nacionales, en los que se discrimina y desprecia a las personas no profesionales. De fracasar en el objetivo de volverse profesional, el joven tendrá que aceptar vivir una vida que desde niño ha aprendido a despreciar. Una vida que, además, por las condiciones laborales de Nauta, probablemente será de pobreza y precariedad.

Esta situación se complejiza aún más a partir de uno de los discursos más descuidadamente impartidos en la escolarización peruana: que el esfuerzo es el camino para el éxito y que, con perseverancia, se puede sortear cualquier dificultad. La mayoría de escolares en Nauta están convencidos de que su éxito depende exclusivamente de ellos mismos.

Entrevistadora: ¿Y qué dificultades pueden tener en el camino?

Entrevistada: Cuando uno se desanima, por ejemplo, no postula, y eso le hace que ya no quiero hacer eso, no quiero hacer el otro (Mujer, 12 años, 2016).

Esta manera de pensar se vuelve sumamente riesgosa cuando el alumno fracasa, pues termina atribuyéndose toda la responsabilidad y la culpa. Pese a que, desde el inicio, los jóvenes se enfrentan una serie de condiciones sociales y económicas que hacen muy improbable que alcancen el proyecto de vida que han emprendido, muchos explican su fracaso en términos de no haber sido lo suficientemente buenos.

En ese contexto, el fracaso genera una sensación de frustración que incluso pone en riesgo la vida de los jóvenes.

Yo he escuchado jóvenes sentir esa frustración, de no poder llegar a ser lo que te meten en la cabeza, lo que los maestros te dicen que es lo que tienes que llegar a ser para ser un aporte importante en la sociedad necesariamente tienes que tener una carrera universitaria [...]. Eso también viene desde el colegio y nos repiten: "Estudien para ir a la universidad". 
No te dicen para ir a un tecnológico. Te dicen: "Estudien para que vayas a una universidad y seas alguien en la vida, alguien en la sociedad, alguien útil". O sea, el que no tiene una carrera universitaria, que no tiene una carrera técnica, que tiene su quinto de secundaria, como yo, porque no he podido, entonces ¿no soy nadie? Entonces, ¿cómo hacerle al muchacho ahí?... Oye, yo he estudiado hasta la secundaria y no sirvo. Entonces, en esta sociedad, no sirvo. Entonces, ¿qué hago? Me desaparezco. Porque aquí no hay lugar para mí. Ese es el sentir de la juventud que se siente frustrada por más esfuerzo que haga. (Periodista de Radio Ucamara, 2016)

\section{Estrategias desesperadas}

Debido al grave desencuentro que existe entre las expectativas de los jóvenes y las oportunidades reales que Nauta ofrece, una estrategia para acceder a mejores oportunidades es migrar a otra ciudad. Se suele asumir que todos los jóvenes quieren hacer su vida en otra parte y que el caso de aquellos que no lo intentan responde estrictamente a su incapacidad.

La alta expectativa de salir de Nauta hace de esta localidad un espacio predilecto para el reclutamiento de jóvenes para diversas actividades. Por un lado, muchos varones son reclutados para el ejército, o como obreros para plantaciones de palma aceitera u otros monocultivos a gran escala en diversas localidades de la selva (no necesariamente cercanas a Nauta). Por su parte, las mujeres son reclutadas para ir a trabajar de empleadas domésticas o de meseras a otras localidades. Frecuentemente, los jóvenes aceptan estos trabajos con la expectativa de ahorrar o poder llegar a un lugar más grande, y así poder tener más oportunidades para estudiar. Sin embargo, en ocasiones, estas ofertas resultan siendo insuficientes o, peor aún, trampas. En el caso particular de las mujeres, estas traen consigo otros riesgos importantes, como el de terminar siendo víctimas de trata de personas.

La percepción general es que la trata de personas es un problema grave que va en aumento, especialmente, en las comunidades de la ribera. Si en la ciudad de Nauta las oportunidades de acceder a educación superior son pocas, en las comunidades de la ribera lo son aún más, debido a que muchas de ellas ni siquiera cuentan con centros de educación secundaria. Por ese motivo, jóvenes, incluso menores de edad, buscan la manera de migrar fuera de sus comunidades.

La presidenta de la Asociación de Mujeres Kukama "Huaynacana" señala que la trata de personas es uno de los principales problemas que enfrentan las comunidades de la ribera. Para dar cuenta de la dimensión del asunto, indica que, en la comunidad en la que vive - una comunidad pequeña de tan solo una calle-, en los últimos años, dos menores de edad han sido víctimas de trata. 
Lo que pasa, la realidad, hay jóvenes que han tenido el deseo de estudiar, de seguir más adelante, pero en realidad no hay posibilidades. Entonces, ellos miran la realidad: “iqué hago yo acá? Tengo que salir a buscar trabajo" [citando lo que dicen los jóvenes]. Los jóvenes van arriesgando su vida y eso es el problema, no solamente aquí sino a nivel de toda la ribera. Eso es lo que está pasando ahorita. (Presidenta de Huaynacana, 2016).

La trata de personas está, en buena medida, relacionada con la imposibilidad que tienen los jóvenes de salir adelante en sus propias comunidades o por sus propios medios. Incluso, en uno de los casos atestiguados por la presidenta de Huaynacana, un proxeneta utilizó este discurso para manipular a la madre de la víctima.

Ahí no le dejaron entrar [a la madre] ni conversar porque decían que "No, tú no tienes derecho de conversar con la fulana, porque ya no es tu hija. Está llevando mi apellido. Yo le estoy haciendo estudiar, es que allá no tiene oportunidad de estudiar". (Presidenta de Huaynacana, 2016)

Otra estrategia utilizada por los jóvenes para intentar acceder a mejores oportunidades es jugar a la ouija. La ouija en Nauta se juega de una manera muy particular, que incorpora elementos culturales sobre el trato con espíritus propios de la tradición kukama. En la cosmovisión kukama, ríos, lagunas y bosques están habitados por espíritus que se relacionan constantemente con los humanos. Estos pueden sanar, hacer daño, tomar posesión de un cuerpo débil, enseñar, entre otros (Regan, 1993). En esa tradición, la magia negra es un conjunto de prácticas y saberes que permite vincularse con espíritus malignos. La ouija incorpora varios elementos de esta y la vuelve accesible a cualquiera que lo desee. De esa manera, el juego termina siendo un canal a disposición de los escolares para hacer tratos con espíritus malignos o-como los llaman aquellos con más influencia evangélica o católica- "el diablo".

Para que ellos [los espíritus] te concedan eso, tú tienes que hacerles un favor. Tú quieres dinero, pero para que ellos te den te van a decir: "Quiero que hagas esto; quiero que mates a tal persona”, así. Tiene su costo. Un intercambio, como se puede decir. Eso sí he escuchado. Así como los brujos: "Tú tienes que pagarle para que haga daño a otro". Y, luego, al que le hizo el daño tiene que ir al mismo brujo y pagarle para que te saque ese embrujo. Al brujo tú le pagas, pero en la ouija es más fuerte porque en sí es un demonio; es tratar directamente con el que está ahí abajo. (Mujer, 14 años, 2016)

$\mathrm{Al}$ igual que lo que sucedía con la estrategia de migrar, la falta de recursos a disposición de los jóvenes para alcanzar sus metas de manera autónoma es lo 
que vuelve atractivo a este juego. Esto se puede ver incluso en la forma en la que se invita a nuevos miembros a incorporarse a las ceremonias.

De esa manera, cuando salimos de ahí me empezó a explicar. "Yo no puedo estar ahí", le decía. "Yo puedo ser pobre, pero no puedo estar en esas cosas metida". Entonces me dijo: "Sí, vas a tener todo lo que tú quieres, puedes pedir, hacer un deseo y todo se te va a cumplir." $Y$, así, seguí yendo a las reuniones. (Mujer, 29 años, 2016)

Por ese motivo, muchos de los que deciden jugar lo hacen con las mejores intenciones. La esperanza de una mejor calidad de vida es el gancho de atracción de la ouija.

Siempre le decía a mi abuelita: "Algún día, mamita, cuando yo sea profesional, yo te voy a sacar de acá", le decía. "Sí mamita, vas a ver; de acá a un año voy a tener harta plata". - ¿De dónde vas a sacar? - "Yo sé. A mí el diablo me va a ayudar", le decía. (Hermana de varón que se suicidó, 2013)

Porque anteriormente mi hijo, antes de que fallezca, me decía: "Mira, mamita, este año nomás vas a trabajar duro, mamita, para que me sirvas. Cuando yo termino, tú ya no vas a trabajar, porque nosotros vamos a tener bastantes cosas. Nosotros vamos a ser algo en la vida". (Madre de varón que se suicidó, 2013)

\section{Cuando se acaban los recursos}

No, no me importaba qué me iba a pasar después. En ese momento, no te importa nada; solo quieres hacer que esto acabe. No te importa. "Ya quiero que acabe; no quiero más esto".

(Mujer, 14 años, 2016)

Pese a que no existen registros confiables que den cuenta de ello, para los nautinos fue evidente el incremento en la magnitud de suicidios de jóvenes alrededor de la época de la construcción de la carretera. El 12 de enero del 2003, el diario La Región reportó el quinto suicidio en tan solo 2 meses, con el titular "Ola de suicidios alarma Nauta". Desde entonces, ha habido épocas más críticas y épocas más tranquilas, pero los suicidios juveniles no han dejado de ser una constante.

Ante la falta de estadísticas confiables, el testimonio de los jóvenes puede dar una imagen aproximada del panorama. Es común entre ellos, especialmente los que se encuentran en edad escolar, haber visto compañeros que se cortan 
el brazo para botar el estrés o el dolor. Estas actitudes las relacionan con comportamientos suicidas.

Asimismo, muchos declaran haber pensado seriamente en suicidarse o haberlo intentado. De una muestra de 36 jóvenes, 21 dijeron que nunca habían considerado suicidarse; 10 , que lo habían pensado seriamente; y 5 , que habían llegado a intentarlo al menos una vez. Estos datos presentan un panorama realmente preocupante.

De una muestra de 55 casos de suicidio entre el 2002 y el 2016, se observa que el $90 \%$ de los suicidas tenía entre 14 y 24 años. Asimismo, se ha identificado que las mujeres eran más jóvenes que los hombres al cometer el acto: la mayoría de mujeres aún estaba en edad escolar, mientras que la mayor parte de los hombres ya había terminado la secundaria.

La mayoría de los nautinos explica los suicidios haciendo referencia al juego de la ouija, a problemas familiares, problemas económicos, problemas amorosos, consumo de drogas o alcohol, o embarazos no deseados. No obstante, atribuirlos a un factor aislado o solo considerar el detonante del acto no permite comprender tal decisión a profundidad.

Benjamin Orlove (1981) plantea que las personas tomamos decisiones sobre nuestras vidas sopesando cuatro factores: nuestras limitantes (condiciones externas que restringen nuestras posibilidades), nuestras estrategias, nuestras metas y nuestros recursos. Además, propone que actuamos distintamente dependiendo de si nos encontramos en una situación normal o en una situación de crisis. Si analizamos los suicidios juveniles desde esa perspectiva, sale a la luz que el grueso de los jóvenes que decidieron terminar con su vida lo hizo tras agotar los recursos de los que disponían para acceder a una carrera universitaria. Más allá de los detonantes y de las particularidades, esta es la constante que se repite en la mayoría de los casos. Por ejemplo, un joven de 24 años cuya familia lo había ayudado a ser policía, trabajaba como tal para ahorrar con el fin de estudiar una carrera profesional. Tras enterarse de que su pareja estaba embarazada, decidió suicidarse y dejó la siguiente carta:

Queridos padres por favor perdónenme que los he hecho sufrir tanto. Yo he sido un hijo q no les ha sabido aprovechar durante los años q han pasado. Sé que ustedes han deseado que sea algo en el futuro pero la suerte no fue así. También mi meta era ser profesional más adelante y ya lo estaba logrando pero lamento mucho mi decisión que he tomado yo porque tenía un problema que no iba a solucionar jamás. [...] Yo también hubiese querido ver nacer a mi hijo que viene en camino y hubiese sido orgulloso de tenerla entre mis brazos junto a su madre que tanto la amaba y espero que mis padres la apoyen en lo poco que puedan porque ella no se merece sufrir y no quiero que le echen la culpa de esto a ella o papá y mamá. No olviden que ustedes fueron los mejores padres que muchos quisieran tener. (Registros de la Fiscalía Penal, 2008) 
En este caso, el embarazo impone una nueva limitante al joven: ahora debe mantener a su bebé y, probablemente, también a su pareja. Esta situación genera que el único recurso que tiene para intentar ser profesional, trabajar como policía, se vuelva insuficiente. Poco después de recibir la noticia del embarazo, en plena situación de crisis, decide suicidarse.

Resulta ilustrativo analizar los suicidios de los jóvenes nautinos, a la luz de las reflexiones planteadas por Hicks (2007) sobre el suicidio de población inuit en Canadá. Este autor plantea que la tasa de suicidios en la población inuit aumentó notablemente a la par con una ola de cambios producto de la intensificación de la acción gubernamental en su territorio. Esos cambios impactaron en lo que el autor denomina "el guion de vida de los inuit", que, a grandes rasgos, es la idea que uno tiene sobre cómo debe vivir. De acuerdo con Hicks, entre los inuit, los jóvenes con mayor riesgo de suicidio son aquellos que están situados en algún punto medio entre el "guion de vida" tradicional de los inuit y el "guion de vida" que emerge del nuevo contexto urbano (Hicks, 2007). Entre ellos, los que tienen incluso más riesgo son los que provienen de comunidades y familias en las que el desempleo y la disfunción social son mayores. Por el contrario, las tasas de suicidios disminuyen en los contextos en los que el "guion de vida" urbano es el predominante y hay mayores niveles de desarrollo económico y social, es decir, mejores sistemas de salud, más éxito escolar, más empleo, etc. (Hicks, 2007).

$\mathrm{Al}$ igual que en el caso descrito, Nauta se encuentra en un proceso de cambio social muy intenso, en el que se experimenta una transición de un modo de vida rural a un modo de vida urbano. En ambos, el suicidio aparece como una consecuencia de la frustración de no querer pertenecer a aquello no valorado $y$, a la vez, no poder pertenecer a aquello que uno valora.

\section{Pensando a futuro}

Los discursos y las prácticas que giran en torno a la promesa de la educación en Nauta se pueden encontrar en muchas otras partes del Perú (véase, por ejemplo, Ames 2002; Ames y Rojas 2011). Sin embargo, la falta de estadística confiable sobre suicidios y la tendencia a interpretarlos en función de sus detonantes en lugar de sus causas de fondo no nos permite saber si a nivel nacional también existe una correlación entre suicidios juveniles y fracaso educativo. Este es un punto pendiente a investigar.

De igual manera, el caso nautino deja mucho por reflexionar. Por un lado, nos obliga a preguntarnos por qué, luego de tantos años trabajando por reconocer y valorar la diversidad cultural, la promesa educativa - que a fin de cuentas es una promesa de progreso- se continúa elaborando en términos dicotómicos. ¿Por qué los hijos de los migrantes en Nauta no pueden progresar y, a la vez, llevar un tipo de vida similar a la de sus padres?

Históricamente, la educación en el Perú se ha presentado como la solu96 I ción para que ciudadanos rurales "salgan del atraso", "se superen" y puedan 
"ser alguien". ¿Qué tan críticos somos como sociedad de esos conceptos? ¿Qué plan tenemos en mente cuando repetimos estos discursos?, ¿la inclusión de los pobladores rurales en una sociedad ideal en la que todos sean profesionales y urbanos?

En el 2012, 4 de cada 10 profesionales universitarios peruanos ocupaban vacantes no profesionales y eran sub remunerados (Lavado, Martínez y Yamada, 2014, p. 2). Evidentemente, el proyecto educativo no está satisfaciendo la expectativa. Es importante trabajar para promover que otras ocupaciones también sean valoradas y elegidas por los ciudadanos. Para ello, el primer paso es garantizar que estas dejen de estar asociadas a una vida de pobreza o carencias. Ello no solo requiere de un reconocimiento discursivo, sino también de un cambio en las condiciones materiales para que las personas que elijan esas alternativas puedan vivir una vida digna.

Complementariamente, es necesario reflexionar sobre cuál es el propósito de la educación y promover que las instituciones educativas, sus docentes y su propaganda mantengan discursos coherentes con este. En ningún escenario, la educación debería presentarse como un canal para volver a los alumnos "alguien en la vida", ni un espacio en el que se desvirtúen ocupaciones legítimas y -muchas veces - imprescindibles para el funcionamiento de nuestra sociedad.

En el siglo XX, el Perú tuvo grandes avances en materia de cobertura educativa. Actualmente, los jóvenes de entre 16 y 24 años tienen un promedio de 10 años de educación mientras que, en 1940, menos del 5\% de la población de 15 años a más tenía estudios secundarios (Benavides, 2007, p. 459). Asimismo, en los últimos años, el Estado ha incrementado y mejorado los canales para democratizar el acceso a la educación a través de becas, colegios de alto rendimiento, programas de educación intercultural bilingüe, entre otras importantes medidas.

A pesar de ello, la meritocracia continúa siendo tan irreal como la igualdad de oportunidades. Por ese motivo, es fundamental continuar trabajando para reducir las brechas de acceso y logro educativo, pero también es imprescindible moderar el discurso que asegura que con esfuerzo y perseverancia se puede sortear cualquier dificultad; por ser peligroso y erróneo. La escuela debe motivar a los alumnos a esforzarse por lograr sus metas, pero de una manera saludable. En la consecución de ese objetivo, ignorar o desestimar sus limitaciones resulta contraproducente.

\section{Agradecimientos}

Este trabajo no hubiese sido posible sin el apoyo de la Pontificia Universidad Católica del Perú, la Radio Ucamara y el profesor Óscar Espinosa. 


\section{Referencias bibliográficas}

Agüero, Ó. (1994). El milenio en la Amazonía peruana: mito-utopía tupícocama o la subversión del orden simbólico. Lima: CAAAP.

Ames, P. (2002). Para ser iguales, para ser distintos. Escuela, escritura y poder en el Perú. Lima: Instituto de Estudios Peruanos.

Ames, P., y Rojas, V. (2011). Cambios y oportunidades: la transición de la escuela primaria a la secundaria en el Perú. Lima: Grade.

Ansión, J. (1995). Del mito de la educación al proyecto educativo. El Perú frente al siglo XXI (pp. 507-525). Lima: Fondo Editorial de la Pontificia Universidad Católica del Perú.

Benavides, M. (2007). Lejos (aún) de la equidad: la persistencia de las desigualdades educativas en el Perú. Investigación, políticas y desarrollo en el Perú (pp. 457-483). Lima: Grade.

Berjón, M., y Cadenas, M. A. (2009). La inquietud "se hizo carne"... y vino a vivir entre los Kukama. Dos lecturas a propósito de los pelacara. Estudio Agustiniano, 44, 425-437.

(2011). "Ser dueño": criterio de la familia Kukama. Estudio Agustiniano, 46, 561-595.

Degregori, C. I. (2007). Del mito de Inkarri al mito del progreso: poblaciones andinas, cultura e identidad nacional. Lima: Instituto Constructor.

Hicks, J. (2007). Los determinantes sociales de las altas tasas de suicidio de los jóvenes inuit. Asuntos indígenas, sufrimiento social (pp. 30-37). Copenahue: IWGIA.

Lavado, P. Martínez, J. J., y Yamada, G. (2014). ¿Una promesa incumplida? La calidad de la educación superior universitaria y el subempleo profesional en el Perú (documento de discusión). Universidad del Pacífico, Lima.

Montoya, R. (1980). Capitalismo y no-capitalismo en el Perú. (Un estudio histórico de su articulación en un eje regional). Lima: Mosca Azul Editores.

Orlove, B. (1981). El suicidio de Juanita. América Indígena, 41(1).

Regan, J. (2008). La presencia y ocaso de los cacicazgos tupíes de la Cuenca del Alto Amazonas en los siglos XVI y XVII. Amazonía Peruana, 31, 57-100. Lima: CAAAP.

(1993). Hacia una tierra sin mal. Iquitos: CETA.

Rivas, R. (2000). Los cocama cocamilla en la varzea de la Amazonía peruana (tesis de pregrado). Ciencias Sociales, Pontificia Universidad Católica del Perú, Lima.

Stocks, A. (1981). Los nativos invisibles. Notas sobre la historia y realidad actual de los Cocamilla en el río Huallaga, Perú. Lima: CAAAP. (1983). Native enclaves in the upper amazon: A case of regional nonintegration. Etnohistory, 30(2), 77-92. 